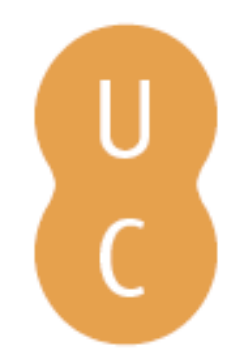

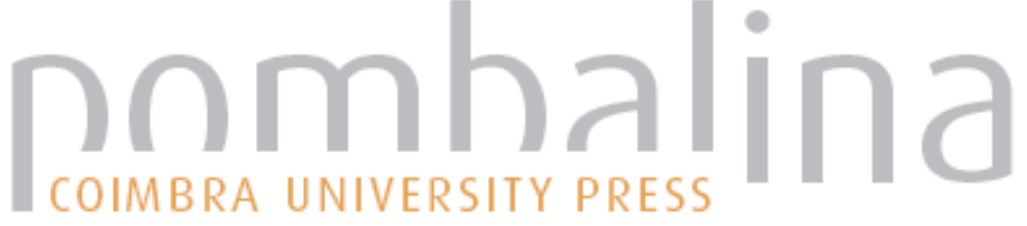

\section{O romance dramático de Adonias Filho: a mobilidade dos procedimentos}

\author{
Autor(es): $\quad$ Mota, Marcus \\ Publicado por: Imprensa da Universidade de Coimbra; Annablume \\ URL \\ persistente: URI:http://hdl.handle.net/10316.2/40873 \\ DOI: $\quad$ DOI:https://doi.org/10.14195/978-989-26-1288-1_13
}

Accessed : $\quad$ 26-Apr-2023 02:39:14

A navegação consulta e descarregamento dos títulos inseridos nas Bibliotecas Digitais UC Digitalis, UC Pombalina e UC Impactum, pressupõem a aceitação plena e sem reservas dos Termos e Condições de Uso destas Bibliotecas Digitais, disponíveis em https://digitalis.uc.pt/pt-pt/termos.

Conforme exposto nos referidos Termos e Condições de Uso, o descarregamento de títulos de acesso restrito requer uma licença válida de autorização devendo o utilizador aceder ao(s) documento(s) a partir de um endereço de IP da instituição detentora da supramencionada licença.

Ao utilizador é apenas permitido o descarregamento para uso pessoal, pelo que o emprego do(s) título(s) descarregado(s) para outro fim, designadamente comercial, carece de autorização do respetivo autor ou editor da obra.

Na medida em que todas as obras da UC Digitalis se encontram protegidas pelo Código do Direito de Autor e Direitos Conexos e demais legislação aplicável, toda a cópia, parcial ou total, deste documento, nos casos em que é legalmente admitida, deverá conter ou fazer-se acompanhar por este aviso.

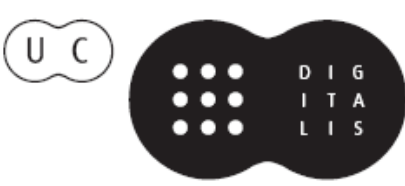




\section{Cosmópolis}

\section{mobilidades culturais às origens do pensamento antigo}

Gabriele Cornelli, Maria do Céu Fialho e Delfim Leão

\section{(coords.)}

IMPRENSA DA UNIVERSIDADE DE COIMBRA 


\title{
O romance dramático de Adonias Filho: A MOBILIDADE DOS PROCEDIMENTOS
}

(The dramatic Novel of Adonias Filho: the mobility in the way of procedures)

\author{
Marcus Mota (marcusmotaunb@gmail.com) \\ Universidade de Brasília - Laboratório de Dramaturgia
}

\begin{abstract}
Resumo: O romance dramático de Adonias Filho propõe um diálogo criativo com a tradição clássica, produzindo um encontro e tensão entre técnicas narrativas modernas e processos criativos do teatro grego antigo. Neste texto, procura-se explicitar este diálogo criativo por meio de referências às obras narrativas e teóricas de Adonias Filho e pela retomada da questão da tipologia de modos narrativos proposta por Platão em A República 392d.

Palavras-chave: Adonias Filho; teatro grego; romance moderno; teoria narrativa; recepção.
\end{abstract}

Aвstract: Adonias Filho is a Brazilian novelist who wrote his works mixing Classical tradition and modern narrative techniques. This fusion of traditions constitutes a unique narrative experiment. In this paper, it is revalued by references to Adonias Filho's fictional and theoretical works and to Plato's theory of narrative modes as set out in Republic 392d.

Keywords: Adonias Filho; Greek theatre; modern novel; narrative theory; reception

\section{INTRODUÇÃo}

Na trilogia composta por Servos da Morte (1946), Memórias de Lázaro (1952), Corpo Vivo (1962), podemos observar o experimento ficcional de Adonias Filho (1915-1990) em transpor procedimentos compositivos da dramaturgia ateniense para a narrativa.

Nesse sentido, forma-se um curioso hibridismo que reivindica estratégias interpretativas específicas. Pois, na recepção e redefinição da tradição teatral ateniense, temos agora não uma diálogo entre figuras e temas, e sim de processos criativos.

Especialmente no romance Memórias de Lázaro, a técnica coral de composição é rearticulada por meio de uma justaposição de procedimentos vindos do cinema, da narrativa e poesia modernas.

Desse modo, o esclarecimento do dramaturgia narrativa de Adonias Filho pode iluminar não apenas aspectos da recepção da tragédia grega como também processo criativos da dramaturgia ateniense mesma.

A hipótese aqui levantada é a seguinte: na elaboração de seu experimento narrativo híbrido Adonias Filho age duplamente como produtor de realizações ficcionais e pesquisador/intérprete do material fonte estudado. Tal 
desdobramento transforma a criação de romances em poéticas que tanto podem ser vistas como esclarecimentos de materiais prévios como disponibilização de recursos que podem ser apropriados e transformados em outros atos criativos.

Diante disso, a partir do caso Adonias Filho proponho que o eixo continuidade/descontinuidade da tradição clássica possa ser também compreendido a partir da mobilidade dos procedimentos, ou da comunidade que se forma no jogo entre processos criativos que são retomados e transformados. Ou seja, enfatiza-se a dimensão criativa da tradição em sua constante reinvenção.

Creio isso ser considerado relevante, ainda mais quando nos aproximamos do centenário de Adonias Filho, a ser celebrado em 2015.

\section{Discursos e revisões}

Nas palavras iniciais de seu discurso de posse na Academia Brasileira de Letras, em 28 de Abril de 1965, Adonias Filho afirma: "O encontro que a Academia permite, fora da contemporaneidade, explica o que possa ser o mistério das aproximações entre certos homens. Em suas gerações distantes, ultrapassando os problemas imediatos, suprimem todas as diferenças impostas pelo tempo para que subsistam as afinidades no sentido de percepção para com os extremos valores da vida. E, já iguais pela vocação, robustecem o grande encontro na exploração da mesma temática e na reivindicação das gerações. Esse encontro se capaz de explicar a compreensão crítica - como na exegese de Dante feita por T. S. Eliot, como no reconhecimento de Pascal, feito por François Mauriac -, assegura que os escritores se congregam em torno de motivos permanentes. Dir-se-ia o caminho interior por onde passam, confirmando que há força na tradição dos próprios valores que estabelecem as aproximações ${ }^{1}$."

Tais palavras buscam conceptualizar a rotina de um ritual que põe em funcionamento a continuidade de uma instituição cuja longa história dialoga com a reinvenção da tradição clássica. No caso de Adonias, esse encontro ou associação entre escritores e intelectuais é vista no jogo entre a pluralidade de tempos/espaços e uma unidade, um núcleo de temas e valores. Ou seja, a entrada nesse grupo seleto faculta a Adonias Filho o exercício de reflexão sobre sua pertença à tradição literária, fazendo com que se coloque em um primeiro plano não o indíviduo mas a explicitação do contexto de consórcio de figuras distintas. Em todo caso, para Adonias em primeiro plano fica a lógica histórico-cultural dos eventos, a racionalidade dos atos expressivos.

Adonias Filho foi nesse dia recebido em discurso de Jorge Amado, que durante sua vida faria apenas um outro, vinte seis anos depois deste, saudando o dramaturgo Dias Gomes. A singularidade dessa convergência de ocasiões dá

\footnotetext{
${ }^{1}$ http://www.academia.org.br/abl/cgi/cgilua.exe/sys/start.htm?infoid=19\&sid=230
} 
a oportunidade de o baiano mais famoso celebrar aquele que considerava um escritor singular, mestre da ficção ${ }^{2}$, corroborando o que o Dias Gomes haveria de enunciar em seu discurso de posse, que ratificava opinião comum de Adonias Filho ser colocado "muito justamente no nível de Machado, de Graciliano e de Guimarães Rosa”. Contudo, em que pese a admirada consensual excelência da produção adoniana, já em 1991 Dias Gomes aponta para os limites da recepção dessa obra, ao comentar que "Adonias ainda não teve a sua obra devidamente dimensionada. Talvez por nunca ter-se deixado seduzir pela popularidade, mantendo-se fiel a seu projeto artístico, sem concessões. Como seus personagens, seguiu sempre seu áspero caminho, que parece previamente traçado, em linha reta, indiferente aos atalhos, prisioneiro da maravilhosa maldição de não poder se deixar cair em tentações. Essa postura estóica pode levar a uma rotulação equivocada de elitismo ${ }^{4}$."

O recurso aos comentários de Jorge Amado e Dias Gomes concretiza aquele jogo histórico-cultural, aquela dinâmica da Tradição referidos por Adonias Filho. Nas cerimônias de posse, o eleito faz um discurso tentando situar-se a partir dos antigos detentores da cadeira. E um integrante atual da academia faz um discurso sobre a obra e a figura de quem agora é empossado. Neste jogo e nesta dinâmica, por exemplo, a Jorge Amado coube saudar a entrada de Adonias Filho em 1965 e o substituto deste, Dias Gomes, em 1991. Dessa maneira o discurso de posse de Dias Gomes se torna tanto uma reavaliação da obra de Adonias Filho e do discurso de Jorge Amado em 1965, quanto uma reiteração do funcionamento da instituição. Novamente, como fora apontado por Adonias Filho, temos o entrechoque entre a cronotopia heterogênea e orientação de unidade ou unificação do processo.

A entrada de Adonias Fiho na Academia Brasileira de Letras pode ser vista como o começo do fim, a sua akmé. O escritor cede lugar ao «intelectual orgânico», cujas ideias serão cooptadas pelo regime militar em vigor. A ambivalência dessa sua posição como esteta e «amigo dos militares» contribuiria e muito, além das razões apontadas por Dias Gomes, para o ostracismo da obra de Adonias Filho 5 .

Naquele momento Adonias Filho havia acabado de lançar sua obra $O$ Forte, obra que marcava tanto uma redefinição de suas experimentações narrativas, ao

${ }^{2}$ http://www.academia.org.br/abl/cgi/cgilua.exe/sys/start.htm?infoid=13557\& sid=244

http://www.academia.org.br/abl/cgi/cgilua.exe/sys/start.htm?infoid=13550\&sid=231. Assis Brasil reafirma este parecer ao asseverar em 1969 que "a ficção brasileira está hoje entregue a quatro escritores, todos já plenos e amadurecidos(não diria realizados) em sua carreira literária. Há um morto, João Guimarães Rosa. Os outros são Clarice Lispector, Autran Dourado e Adonias Filho. (...) Os nomes apontados atrás e surgiram mais ou menos na mesma época, entre 1944 e 1946" ( Assis Brasil 1969: 15).

${ }^{4}$ Idem.

${ }^{5}$ Expressão em Jorge 1999: 412. Para a questão de intelectual orgânico, v. Gramsci 1978, Silva 2011. 
valer-se, entre outras coisas, de ambiente urbano, quanto ratifica aquilo que desde o primeiro romance, Servos da Morte (1946), Jorge Amado qualifica de uma produção "de densidade pouco comum em nossa Literatura, onde as figuras se movem num baixo relevo de tragédias(...) as vossas criaturas estão presas nas malhas de um destino sempre terrível, ao qual não podem escapar"

As associações da obra de Adonias Filho com termos relacionados à dramaturgia ateniense não são marginais. As três primeiras obras de Adonias Filho são consideradas uma trilogia, a 'trilogia dos campos do sul da Bahia' ou trilogia do cacau. Na maioria da vezes, porém, essas associações se referem ao conteúdo textualizado, aos signos de 'primitiva violência', 'atalho de horrores e misérias, de angústias e brutalidades' que abundam em Servos da Morte, Memórias de Lázaro(1952), Corpo Vivo(1962) 7 . Em outras palavras, tais expressões traduzem a percepção da tragicidade, do conteúdo trágico como efeito das narrativas.

Uma faceta pouco comentada na recepção da obra adoniana proporciona um melhor esclarecimento desse efeito narrativo. Trata-se da produção ensaística de Adonias Filho.

Relembrando em entrevista sua carreira, Adonias Filho afirma que "já naquele momento, no rapaz de dezoito anos, as exigências da ficção de tal modo pareciam um desafio que chegou à crítica literária como uma maneira de - estudando os outros - aprender a trabalhar os próprios romances. Os meus primeiros artigos publicados, ainda aos 18 anos, no Diário de Notícias, de Salvador, foram de crítica literária (van STEEN 2008:162). “

Como se pode concluir, Adonias Filho se inicia-se como escritor na função de leitor profissional, no diálogo de aprendizagem com outros escritores. Nos artigos tal dimensão é bem clara: o foco do comentário não é o de uma apreciação valorativa individual da obra, e sim do estabelecimento de vínculos da obra analisada com diversas tradições interconectadas: a nacional, com suas várias historicidades, e internacional, entre a produção européia e a norte-americana. No entanto, mais que a correlação entre obras e tradições, temos o foco nas técnicas narrativas, naquilo que, ao falar de seu trabalho com Memórias de Lázaro, ele denomina "o romance como uma obra de arte(...) sua configuração arquitetônica ${ }^{8}$. Para Adonias, era fundamental, frente à mudança nos modos construção narrativas no século XX, acompanhar "o problema arquitetônico do romance, sua armação plástica, a aplicação do tempo e do espaço ${ }^{9}$ "

O destaque a questões composicionais não se reveste aqui de uma oposição forma $/$ conteúdo $^{10}$. Dirige-se ao momento excepcional da ficção moderna e sua

\footnotetext{
${ }^{6}$ Novamente, trecho do discurso de saudação a Adonias Filho.

${ }^{7}$ Ainda, trechos em aspas do discurso de Jorge Amado saudando Adonias Filho.

${ }^{8}$ van Steen 2008: 163.

${ }^{9}$ Adonias Filho 1965: 9.

${ }^{10}$ Em entrevista, Adonias Filho pondera que "Antes de o escritor poder se dedicar a
} 
proliferação de novos modos de narrar, sua 'revolução na estrutura', na qual "o tronco antigo, da narrativa organizada numa seriação pacífica de episódios, da apresentação direta e objetiva- responsável pelo excesso de detalhes e pormenores inúteis, o movimento lerdo, a focalização paisagística sempre fatigante-, não podia prevalecer em uma espécie de arte organicamente dependente do tempo."11

O deslocamento do ato narrativo para a exploração de suas possibilidades não apenas mobiliza atividades expressivas mais específicas por parte dos narradores: "a aplicação dos elementos, na consideração das perspectivas, no emprego dos suportes, na abertura do roteiro, o romancista pensa compreensivamente no equilíbrio, na proporção em todo um sistema simétrico para a colocação das peças" (Adonias Filho 1958: 23); há também a abertura para outras áreas de conhecimento e arte, com o romance " movendo-se em um espaço amplo que se insere nas conquistas culturais mais recentes - da linguística ao neo-existencialistmo, da renovação plástica à criação cinematográfica ${ }^{12}$."

E como compreender este paradoxo aparente entre o efeito trágico da narrativa e sua atualidade técnica em Adonias Filho? Em parte pode-se interrogar os textos antigos de Adonias, reunidos sobre o título de Jornal de um Escritor. Trata-se de apontamentos críticos, reflexões publicadas em jornais entre 1943 e 1946, relativas a apreciação de ideias, autores e obras européias e norte-americanas. Há toda uma mistura de impressões de limite e esgotamento com as estéticas e produções ali analisadas, como se o enfado vencesse o fascínio da descoberta, como se já não bastasse ler o que outros fizeram, escrever sobre o que os outros estavam escrevendo naquele tempo. Tal aura penumbrista retoma valores e posturas de fins do século XIX, com inquietações a partir da busca de alternativas factíveis ou não frente ao presente imediato. Dentro desse espectro cético, Adonias cultiva toda uma fraseologia de forte acento lírico-negativista para caracterizar as obras e autores que comenta. Assim "o terrível drama de consolar na aridez do coração a insatisfação do nosso maior desejo. A fixação da vida que que nasceu irremediavelmente perdida"; "Homem que não se exalta, bem um romancista do nosso tempo, não faz do romance um refúgio" ; "O homem não é totalmente miserável porque sonha, sonha e enlouquece, durante alguns momentos da vida"; "A criatura que delira é a criatura que sofre ${ }^{13}$."

Tais momentos do texto crítico parecem independentes, como uma outra criação: no lugar de se dirigir a comentar a obra lida, Adonias sobrepõe o que

elementos tão importantes como o homem, a realidade, a humanidade, em resumo, ao que definimos aqui como compromisso, deve demonstrar primeiramente que é um escritor. Um conteúdo tão vasto, tão transcendente, uma responsabilidade temática tão grande requer naturalmente a forma digna de tal empresa ( Lorenz 1973:371).

${ }^{11}$ Adonias Filho 1958: 20-21.

12 Adonias Filho 1958: 22.

${ }^{13}$ Adonias Filho 1954: 10, 8, 16, 15. 
escreve a referências e informação ao que leu. O espaço da escritura fica saturado com simultâneos e múltiplos funções e focos. Essa interferência, este ato de apor ao outro a sua própria coisa, seu universo particular, desencadeia o efeito de reorientação do leitor que, durante os textos curtos e intensos que usufrui, participa dessa demonstração de construção não de um argumentos, mas de encaixes, recortes, planos unidos em sua descontinuidade.

Assim, o máximo de atualidade, de presentismo acaba por ser lançar o autor em um dupla espiral: em uma crise, em um senso de desconexão frente ao imediato; e uma revisão de sua historicidade. Se o melhor de hoje não é o suficiente, se o agora não me basta ou sustenta, é preciso ir além, romper com a ilusão do presente como algo dado, fechado. Essa busca por horizontes e fundamentos é tratada nos apontamentos sobre a renovação do Espírito da Tragédia. Na acumulação de temas e autores deste tópico de página e meia - Homero, Platão, Sófocles, Eurípides, Tito Lívio, Petrarca, Nietzsche)-, Adonias Filho centra-se na discussão da tradição clássica, de sua dinâmica histórico-expressiva. A problematização do presente passa pelos modos como a tradição clássica foi revisitada.

Adonias Filho refina mais a que classicismo este ele e suas implicações de seu projeto artístico quando passa de valer-se de vocabulário relacionado ao trágico para locomover-se dentro da dramaturgia mesma.

Para precisar tal procedimento, é preciso retornar à retórica da academia. Em 16 de Outubro de 1967, a saudar o empossado acadêmico Joracy Camargo, homem de teatro, autor de dezenas de textos teatrais, entre eles,» Deus lhe Pague»(1933) ${ }^{14}$, Adonias Filho detem-se em reflexão histórico-cultural do teatro ocidental. Para Adonias, "dentre as artes, nenhuma será mais receptiva que o teatro. E receptiva no sentido da interferência cultural15" Essa excepcionalidade da teatralidade como matriz cultural é assim desenvolvida: "Se a pesquisa é feita, no fundo da auscultação que toma culturalmente as fundações será fatal que o vejamos (o teatro) mobilizando os elementos ficcionais da epopeia para transmiti-los à Novelística nos países velhos.”

\section{Teatro e narrativa}

Como ex-professor de Teoria e História do Teatro (e dramaturgo bissexto), Adonias retoma um tópico fundamental da dramaturgia ateniense, o de suas relações com a épica homérica, tópico que pode ser lido em outra via, como na definição teatral da épica homérica, proposto por Platão. Hoje sabemos que o tema é bem mais complexo: a formação daquilo que chamamos 'teatro grego' não se deu em um vazio de formas e tradições performativas. Antes, não apenas a épica foi apropriada e transformada: no contexto do que podemos chamar "gênero

\footnotetext{
${ }^{14} \mathrm{http} / / /$ www.academia.org.br/abl/cgi/cgilua.exe/sys/start.htm?infoid=12815\&sid=230

${ }^{15}$ Seguem-se em aspas trechos deste discurso de recepção a Joracy Camargo.
} 
coral" temos a intersecção multilateral entre lirismo coral trágicos e não trágico, estes como o Peã, o Epinício, a Partenéia, o Himeneu e o Trenodia ${ }^{16}$. Por outro lado, no decorrer de seu primeiro século, a dramaturgia não apenas absorveu outras tradições performativas e as modificou, como se impôs hegemonicamente ${ }^{17}$.

Assim, o esboço histórico-cultural de Adonias Filho o mais importante é que o teatro articula-se no meio, no espaço entre a épica e a narrativa. Dessa maneira, a novelística é herdeira desse hibridismo, dessa campo intergêneros entre teatro e épica.

Nesse sentido é importante retomar as colocações de Platão, que acusa o Homero de ser "o primeiro mestre e guia de todos esses belos trágicos" ou "o primeiros dos tragediógrafos" ${ }^{18}$. Ora nisso, no encontro entre a Adonias Filho e Platão, temos que se Homero é trágico, dramático, é por que o teatro é épico. Assim, compreender a teatralidade de Homero torna possível compreender a epicização da cena.

Para tornar esse tópico mais claro, é razoável ter em mente que estamos falando de tradições performativas em contato. $\mathrm{O}$ que determina a reciprocidade reside no modo de sua articulação, de organização efetiva de seu modo de produção de efeitos.

A teoria dos três modos de articulação narrativa no livro terceiro de A República (392d), mesmo que construída como uma refutação de atos performativos, subsidia o entendimento das fronteiras entre teatro e narração ${ }^{19}$. Platão postula a existência de três modos narrativos: 1- a narrativa simples ou sem mistura (haple diegesis) ou narrativa autorial, restrita à voz de seu emissor, ao seu suporte discursivo único; 2-narrativa mimética ou por meio de mímesis (diegesis dia mimeseos) em que cada figura se apresenta em sua própria voz, como no discurso direto; 3- narrativa mista ou por meio de ambos os modos supracitados (diegesis di'amphoteron), na qual se encontram presentes tanto uma voz narrativa autoral quanto vozes de outras figuras.

Como se pode observar, o modelo tripartite na verdade é dicotômico: há uma distinção entre diegesis e mimesis, e entre a identidade de um discurso baseada na identidade singular ou plural de seus articuladores ou figuras. Nos exemplos dados por Platão essa distinção é aclarada:

\begin{tabular}{|l|l|l|}
\hline \multicolumn{1}{|c|}{ TIPO } & \multicolumn{1}{c|}{ DESCRIÇÃO } & \multicolumn{1}{c|}{ EXEMPLO } \\
\hline Simples & "narração do próprio poeta" & Ditirambo \\
\hline Mimético & "Espécie que é toda imitação & Tragédia, Comédia \\
\hline
\end{tabular}

\footnotetext{
${ }^{16}$ Swift 2010.

${ }^{17}$ Herington 1985.

${ }_{18}$ Platão, República 595b, 607a.

${ }^{19}$ Para uma análise do trecho, v. Halliwell 2009, Brandão 2006.
} 


\begin{tabular}{|l|l|l|}
\hline Misto & “constituída por ambas” & $\begin{array}{l}\text { na Epopéia e em muitos } \\
\text { outros gêneros }\end{array}$ \\
\hline
\end{tabular}

A partir dessas distinções e exemplos as aproximações entre épica e teatro se fazem notar. O que as aproxima é a mímesis, aqui entendida como "fazer seus discurso como se fosse outra pessoa (393c).” Tanto que a narrativa simples é produzida por Platão quando de um trecho de Homero reescrito e a partir da redução da mímesis ou centralização narrativa ema um voz única que apresenta o que aconteceu com as outras pessoas no lugar delas mesmas enunciarem a respeito de si mesmas (393c, d). Assim, no início de a Ilíada, seguimos "o próprio poeta que fala e não tenta voltar o nosso pensamento para outro lado, como se fosse outra pessoa que dissesse e não ele. E depois disto fala como se Crises fosse ele mesmo e tenta o mais possível fazer-nos supor que não é Homero que fala, mas o sacerdote, que é um ancião (393a, b)" neste caso temos em sequência o uso de narrativa simples e por mímesis.

Desse modo, tanto na narrativa mimética quanto na mista ou composta temos situações em que as personagens falam por sua própria voz, estão presentes no texto como agentes do discurso, identificáveis não apenas por uma voz que se estende por toda a narrativa, mas também por aquilo que elas mesmas enunciam.

Assim, a aproximação entre dramaturgia e épica, tema recorrente nas teorias teatrais e narrativas divisado em Adonias Filho aqui encontra, em parte, sua contextualização conceptual: Adonias Filho aponta para uma matriz dramática existente na Epopéia e que três mil anos depois se encontra na atividades do romance contemporâneo. No caso de Platão, há a identificação de procedimentos narrativos, de manipulação das vozes do discurso. Em um e outro caso, o diferencial é o dramático, a presença de vozes plurais no discurso. Mais ainda: que haja a personificação ou desdobramento personativo, o narrador deixando de ser a única instância de referência do discurso para que a multiplicação de outras instâncias ${ }^{20}$. Com isso, a matriz dramática é o da moldura de um deslize ou uma fronteira instável entre o contar e o mostrar.

Adonias Filho, no mesmo discurso de saudação ao dramaturgo Joracy $\mathrm{Ca}-$ margo volta ao tema, agora com o foco em sua contemporaneidade e atividade de romancista: " $E$ a acrescento que, descendendo da epopéia -sempre os poema épicos que inspiraram o Teatro Grego e, equivale dizer, o Teatro Ocidental de Ésquilo aos contemporâneos -, o Romance, nem por se o mais recente gênero literário, perde sua natureza clássica. Na motivação clássica é que se vai apoiar, já em nosso século, a sua grande revolução . ${ }^{21 "}$

${ }^{20}$ V. De Jong 1987:1-14, Halliwell 2009,Kirby 1991, Brandão 2006, Brandão 2007, Halliwell 2012.

${ }^{21}$ Ainda trecho do discurso de recepção a Joracy Camargo. 
Se a chamada revolução na estrutura da narrativa moderna passa pelo diálogo com a tradição clássica, se a arqueologia histórica de Adonias Filho nos direciona para as matrizes dramáticas, em que termos se dá essa mediação histórico-expressiva da teatralidade?

A distinção e tensão entre modos narrativos diversos foi utilizada pelos narradores modernos como seu campo de experimentação. Ponto comum e determinante para isso foi descentralização narrativa, com proliferação de várias vozes autonomizadas. No texto, "não se trata mais de um sujeito, cujas impressões são reproduzidas, mas de muitos sujeitos amiúde cambiantes ${ }^{22}$." E tal horizonte das vozes autonomizadas em contato tem um nome: coro.

É no romance Memórias de Lázaro que essa 'coralização' ou heterofonia da narrativa melhor se compreende. Eis a abertura, o prólogo da obra:

"Infinita é a estrada com suas curvas, suas colinas e suas árvores. Não é uma estrada como outra qualquer, com pássaros e ladeada de grama, mas uma linha sinuosa no chão avermelhado e seco. Onde começa, ninguém sabe. Onde termina, ninguém sabe também. Tão íntima quanto os rudes objetos das habitações primitivas, para nós que a conhecemos desde crianças, existe quase como uma criatura humana. Insensivel, acolhe-nos com desprezo, sem bondade. Ficássemos cegos e localizaríamos com facilidade todos os cactos que a tornam agressiva, perdêssemos o tato e diríamos sem esforço qual da suas pedras é a mais áspera. Para os outros, os viajantes que por milagre a atravessassem sem conseguir filar os seus segredos, seria apenas uma estrada. Para nós, gente do vale, que a limpamos todos os dias com os nossos pés, que sobre ela suportamos o sol e toleramos a chuva, é o mundo que liga a nossa vida e une as nossas esperanças e sofrimentos. (...)

Mas, o que caracteriza esse vale após este chão, quase uma lava que não esfriou inteiramente, o que caracteriza em todas as partes é o vento perdido.(...)

É provável que venha das montanhas. Sobre a chapada, eco por assim dizer da garganta que separa o vale da montanhas, seu ruído não é áspero, mas também não é rouco. Um lamento que assusta e provoca o endurecimento dos nervos. Em criança, amei-o. Odiei-a seguir. Hoje, não poderia compreender o vale e juro que seria impossível admitir a estrada sem suas rajadas. ${ }^{23}$."

Neste trecho imagens do Vale de Ouro sucedem-se a partir da perspectiva de dois enunciadores: primeiro, o sujeito coletivo dos habitantes do vale; depois, um de seus moradores, o protagonista Alexandre, ainda não nomeado. O Vale de Ouro irrompe terrível, primitivo tão vivo quanto aqueles que o enunciam. A amplitude dessas referências atávicas e rústicas ecoa na amplitude das vozes que a apresentam. Neste ponto aquilo que se mostra ultrapassa seu ponto origem,

\footnotetext{
${ }^{22}$ Auerbach 1971: 483.

${ }^{23}$ Adonias Filho 1978.
} 
sua enunciação. O Vale de Ouro em si mesmo é maior e maior robusto que seus habitantes. Estes são como que abarcados pela coisa narrada. Para quem lê importa mais seguir o fluxo das imagens que a figura que as apresenta. Esse focalização na atualidade daquilo que se mostra subverte o recurso recorrente de se identificar a narrativa como extensão de um programa de interesses e ações de uma exclusiva fonte enunciadora ${ }^{24}$. Nesse sentido aproxima-se daquilo que F. Stanzel denominou de situação 'narrativa personativa, na qual temos "uma disjunção entre narração e perspectiva de personagem ${ }^{25}$ ", o que abre a experiência do leitor para seguir referências a ele dispostas e não indexadas a um constante comentário e sobredeterminação. ${ }^{26}$ Uma série de 'narradores' se sucedem com suas limitadas perspectivas como refletores: vemos por eles o que acontece, eles nos mostram suas limitadas e incompletas experiências.

De volta ao trecho a voz coral dos habitantes do vale que se traduz nas imagens e acontecimentos que projeta para o leitor e em seus diversos e sucessivos enunciadores explicita a mediação histórico-expressiva que Adonias Filho via na teatralidade como link entre a tradição clássica e produção narrativa moderna. $\mathrm{O}$ dramático em Adonias Filho, essa transhistoricidade da matriz dramática, não reside na oferta de eventos funestos. A recurso ao campo de referências cênicas reside na vinculação de procedimentos, de modos de organizar e veicular essa organização.

Antes de Homero e a partir dele, o vínculos entre a comunidade e suas narrativas puderam adquirir um modo de construção que estabelecia algumas isomorfias entre o contexto de performance narrativa e os próprios produtos dessa performance. Entre elas, o performer engaja-se em um jogo com sua atividade diante da audiência, de forma a fundir-se com ou se distinguir quanto as figuras que apresenta. Este jogo entre performer, comunidade e mundo representado encontra no modelo épico-dramático de Homero uma exploração de suas possibilidades. A Ilíada e a Odisséia são documentos dessas possibilidades. Como ficções exploratórias, os textos homéricos se oferecem como novos pontos de partidas para novos empreendimentos expressivos, como o foram para o teatro grego, para a filosofia platônica e para o antigo romance grego, entre outros ${ }^{27}$.

No caso de Adonias Filho, digno de nota é o fato de a recepção dessa tradição ser bipartida, entre esboços ensaísticos e textos ficcionais. No caso destes últimos, pode-se ver, assim como Adonias Filho apontou em seu discurso de posse, a constituição de um diálogo que atravessa tempos e espaços e se completa em uma convergência de esforços. Assim, a transhistoricidade da matriz dramática se materializa em uma comunidade de autores, obras e leitores que

\footnotetext{
${ }^{24}$ V. Stanzel 1977: 92.

${ }^{25}$ Walsh 2010: 44-45.

${ }^{26}$ Stanzel 1971, Stanzel 1986.

27 Para o conceito de 'ficção exploratória', v. Iser 2000.
} 
atravessa os tempos consumidos produtos que parte de procedimentos de organização narrativa a partir de um horizonte performativo do ato narrativo. Essa mobilidade dos procedimentos, porém, não organiza apenas os relatos. Se por modos teatralizados de produção ficcional temos uma heterofonia narrativa com vozes autonomizadas, quem se aproxima dessa tradição dela participa em sua pluralismo focal: Homero não é «o narrador» dessa longa história. Não se pode traçar retrospectivamente uma fonte original responsável por todos os processos posteriores. O que temos é a mobilidade dos procedimentos, que mobilizam leitores e autores na experiência de trânsito entre o acontecer narrativo em sua configuração cênica.

Dessa maneira, o romance dramático de Adonias Filho assim se qualifica não por que expõe o leitor a emoções terríveis, a eventos chocantes: antes, é dramático na participação e exploração das possibilidades do agenciamento da teatralidade da narrativa. 


\section{REFERÊNCIAS BibLIOGRÁficas}

Adonias Filho (1954), Jornal de um escritor. Rio de Janeiro.

Adonias Filho (1958), Modernos Ficcionista Brasileiros. Rio de Janeiro.

Adonias Filho (1965), Modernos Ficcionista Brasileiros. Rio de Janeiro.

Adonias Filho (1978), Memórias de Lázaro. 5a. ed. Rio de Janeiro.

Assis Brasil, F. (1969), Adonias Filho. Rio de Janeiro.

Auerbach, E. (1971), Mimesis. Trad. De G. B. Sperber, S. Paulo.

Brandão, J. (2007), "A Teoria dos gêneros literários e o estatuto da narrativa simples em Platão". Link: http://www.letras.ufmg.br/jlinsbrandao/JLB_ teoria_generos_literarios.pdf.

Brandão, J. (2006), "Traduzir Homero do grego para o grego (as mediações da teoria)", Scripta Classica On-line 2: 5-29. Link: http://www. scriptaclassicaonlinebr.gr.eu.org/textos.html.

Cherniss, H. (1945), The Riddle of the Early Academy. Cambridge.

De Jong, I. (2014), Narratology and Classics. Oxford.

De Jong, I. (1987), Narrators and Focalizers. The Presentation of the Story in the Iliad. Amsterdam.

Dillon, J. (2003), The Heirs of Plato. A Study of the Old Academy (347-274 BC). Oxford.

Gramsci, A. (1978), Os intelectuais e a organização da cultura. Rio de Janeiro.

Halliwell, S. (2012), "Diegesis-Mimesis", in The Living Handbook of Narratology. Link: http://wikis.sub.uni-hamburg.de/lhn/index.php/Diegesis_-Mimesis.

Halliwell, S. (2009), "The Theory and Practice of Narrative in Plato", in J. Grethlein \& A. Rengakos (Eds.). Narratology and Interpretation: the Content of the Form in Ancient Texts. Berlin, 15-41.

Herington, J. (1985), Poetry Into Drama. Early Tragedy and the Greek Poetic Tradition. Berkeley.

Iser, W. (200), "What is literary anthropology? The difference between explanatory and exploratory fictions", in M. Clark (ed.) Revenge of the Aesthetic: the Place of Literature em Theory Today. Berkeley, 157-179.

Jorge, F. (1999), A Academia do fardão e da confusão. São Paulo.

Kirby, J. (1991), "Mimesis and diegesis: foundations of aesthetic theory in Plato and Aristotle", Helios 18: 113-128.

Lorenz, G. (1973), Diálogo com a América Latina. São Paulo.

Mota, M. (2008), A dramaturgia musical de Ésquilo. Brasília. 
Mota, M. (2013), Nos passos de Homero. Ensaios sobre performance, filosofia, música e dança a partir da Antiguidade. São Paulo.

Mota, M. (2014), Imaginação e morte. Ensaios sobre a representação da finitude. Brasília.

Platão (2011), A República. Tradução de M.H. da Rocha Pereira. Lisboa.

Silva, J. (2011), "Intelectual orgânico: organizador, educador e dirigente político", Revista PLURAIS 1: 84-105.

Stanzel, F. (1986), A Theory of Narrrative. Cambridge.

Stanzel, F. (1971), Narrative Situations in the Novel. London.

Swift, L. (2010), The Hidden Chorus. Echoes of Genre in Tragic Lyric. Oxford.

van Steen, E. (2008) ViverEEscrever 3. Porto Alegre: L\&PM.

Walsh, R. (2010), "Person, level, voice. A rhetorical reconsideration”, Link: http://inss.ku.dk/kalendera/fiktionens_forandringer/2_Walsh.pdf 